\title{
The role of smartphones in encouraging physical activity in adults
}

\author{
This article was published in the following Dove Press journal: \\ International Journal of General Medicine \\ I2 September 2017 \\ Number of times this article has been viewed
}

\section{Melanie I Stuckey' \\ Shawn W Carter ${ }^{2}$ \\ Emily Knight ${ }^{3}$}

'Research and Academics, Ontario Shores Centre for Mental Health Sciences, Whitby, ON, Canada; ${ }^{2}$ Eating Disorders Residential Program, Ontario Shores Centre for Mental Health Sciences, Whitby, ON, Canada; ${ }^{3}$ Faculty of Health Sciences, University of Western Ontario, London,

ON, Canada
Correspondence: Emily Knight University of Western Ontario, II5 I Richmond Street, Arthur and Sonia Labatt Health Sciences Building, Room 222, London, ON N6A 5B9, Canada

$\mathrm{Tel}+15196614119$

Email eknigh2@uwo.ca

\begin{abstract}
Lack of physical activity is a global public health issue. Behavioral change interventions utilizing smartphone applications (apps) are considered a potential solution. The purpose of this literature review was to: 1 ) determine whether smartphone-based interventions encourage the initiation of, and participation in, physical activity; 2) explore the success of interventions in different populations; and 3) examine the key factors of the interventions that successfully encouraged physical activity. Eight databases (Medline, Scopus, EBM Reviews-Cochrane Central Register of Controlled Trials, EBM Reviews-Cochrane Database of Systematic Reviews, PsycInfo, SportDISCUS, CINAHL, and EMBASE) were searched and studies reporting physical activity outcomes following interventions using smartphone apps in adults were included in the narrative review. Results were mixed with eight studies reporting increased physical activity and ten reporting no change. Interventions did not appear to be successful in specific populations defined by age, sex, country, or clinical diagnosis. There was no conclusive evidence that a specific behavioral theory or behavioral change technique was superior in eliciting behavioral change. The literature remains limited primarily to short-term studies, many of which are underpowered feasibility or pilot studies; therefore, many knowledge gaps regarding the effectiveness of smartphone apps in encouraging physical activity remain. Robust studies that can accommodate the fast pace of the technology industry are needed to examine outcomes in large populations.
\end{abstract}

Keywords: exercise, public health, mobile health, behavioral change

\section{Introduction}

Non-communicable diseases are the leading cause of mortality and morbidity worldwide. ${ }^{1}$ Lack of physical activity is an important risk factor - ranked fourth, only behind high blood pressure, tobacco use, and high blood glucose. ${ }^{1}$ Global guidelines recommend accumulating 150 min of moderate-to-vigorous intensity physical activity (MVPA) per week to maintain health and prevent or delay the onset of chronic disease ${ }^{2}$; however, in high-income countries, the majority of the population is not sufficiently active. For example, only $15 \%$ of Canadians ${ }^{3}$ and $10 \%$ of Americans ${ }^{4}$ meet physical activity guidelines. Low- and middle-income countries are generally more active, but are experiencing rapid urbanization and globalization, which is causing a shift toward decreased physical activity. ${ }^{2}$ Therefore, increasing physical activity has been identified as an important public health target to reduce the incidence and improve the management of non-communicable diseases. Effective strategies for initiating, increasing, and maintaining physical activity are needed.

Physical activity engagement is a complex behavior influenced by many factors, including social context, self-perceptions, and physical abilities. Behavioral change 
theories have been used as frameworks for physical activity interventions in an attempt to address the challenges associated with the adoption and maintenance of a physically active lifestyle. Interventions that are not purposefully grounded in theory often contain one or more behavioral change techniques. The most effective behavioral change techniques for improving physical activity outcomes have been identified as: teach to use prompts/cues, prompt practice; prompt rewards contingent on effort or progress toward behavior; prompt self-monitoring of behavioral outcome; and plan social support/social change. ${ }^{5}$ Interventions incorporating these behavioral change techniques have the potential to positively and effectively influence physical activity behavior; however, to have global impact, these interventions need to be scalable to apply to a broad population.

Globally, a median of $43 \%$ of adults report owning a smartphone, with a greater percentage of ownership in high- compared with low- and middle-income countries. ${ }^{6}$ Smartphone ownership is increasing at a rapid rate in many low-to-middle-income contries, ${ }^{6}$ increasing the potential reach of smartphone-based interventions. Smartphone applications (apps) are an attractive means of intervention delivery because they are generally readily accessible through apps stores (iTunes and Google Play for Apple and Android devices, respectively) and relatively inexpensive. Mobile health (mHealth) has been suggested as a potential solution to support physical activity behavioral change initiatives because its portability enables interventions to prompt, track, and reward behaviors in a timely manner, and its functionality allows for interactivity and social connectivity (aligning with the most effective behavioral change techniques for physical activity). Apps may further influence behaviors by incorporating persuasive design and gamification components. ${ }^{7}$ Considering the theoretical potential of smartphonebased interventions to encourage physical activity, a closer examination of these studies is warranted. The purpose of this literature review was to: 1) determine whether smartphonebased interventions successfully encourage engagement in physical activity; 2) explore the success of interventions in different populations; and 3) examine the key factors of interventions that successfully encouraged physical activity.

\section{Materials and methods}

\section{Criteria for considering studies for this review}

Studies were included in this review if: 1) the study sample primarily comprised adults aged $\geq 18$ years (one study was included which was intended for people aged $\geq 16$ years);
2) smartphone-based apps were part of the intervention; and 3) physical activity outcomes were reported.

\section{Search strategy}

The search strategy for Medline was: (smartphone* OR smart-phone* OR iphone* OR i-phone* OR "Mobile Health" OR mHealth) AND (physical activit* OR exercis*). The search was limited to the English language, dates January 2007 (the year the first apps were developed) to May 2016 (search last updated May 19, 2016) and limited to articles and reviews published in academic journals. The Medline search strategy was modified as needed for each of the following databases: Scopus, EBM Reviews-Cochrane Central Register of Controlled Trials, EBM Reviews-Cochrane Database of Systematic Reviews, PsycInfo, SportDISCUS, CINAHL and EMBASE.

\section{Data collection and management}

Search results were exported to reference managing software (EndNote X7.5). All abstracts and titles were evaluated according to the inclusion criteria listed earlier. If inclusion criteria could not be confirmed through the abstract, the full text was obtained and evaluated. Data were extracted from the full text of qualifying studies. Data were extracted to describe the population (age, sex, clinical diagnosis, etc.), context (country, setting, etc.), behavioral theory/behavioral change techniques, and physical activity outcomes.

\section{Results}

The initial literature search returned 1,540 articles, 655 of which were identified by reference manager as duplicates (Figure 1). Eight hundred eighty-five titles and abstracts were visually scanned for inclusion. A further 119 were duplicates, and 732 were identified as not applicable to the current review. Therefore, 33 full-text articles were retrieved for further consideration. Of these, 15 were excluded ( $n=14$ did not report physical activity outcomes; $n=1$ reported data already included in a previous study), and 18 studies were included in this review. Table 1 provides an overview of the included studies.

\section{Do smartphone-based interventions encourage the initiation of, and participation in, physical activity?}

The 18 studies that reported physical activity outcomes following smartphone-based interventions showed mixed results. Eight reported increased physical activity following a smartphone-based intervention, ${ }^{11,13,15,19,21,22,24,25}$ and ten studies 


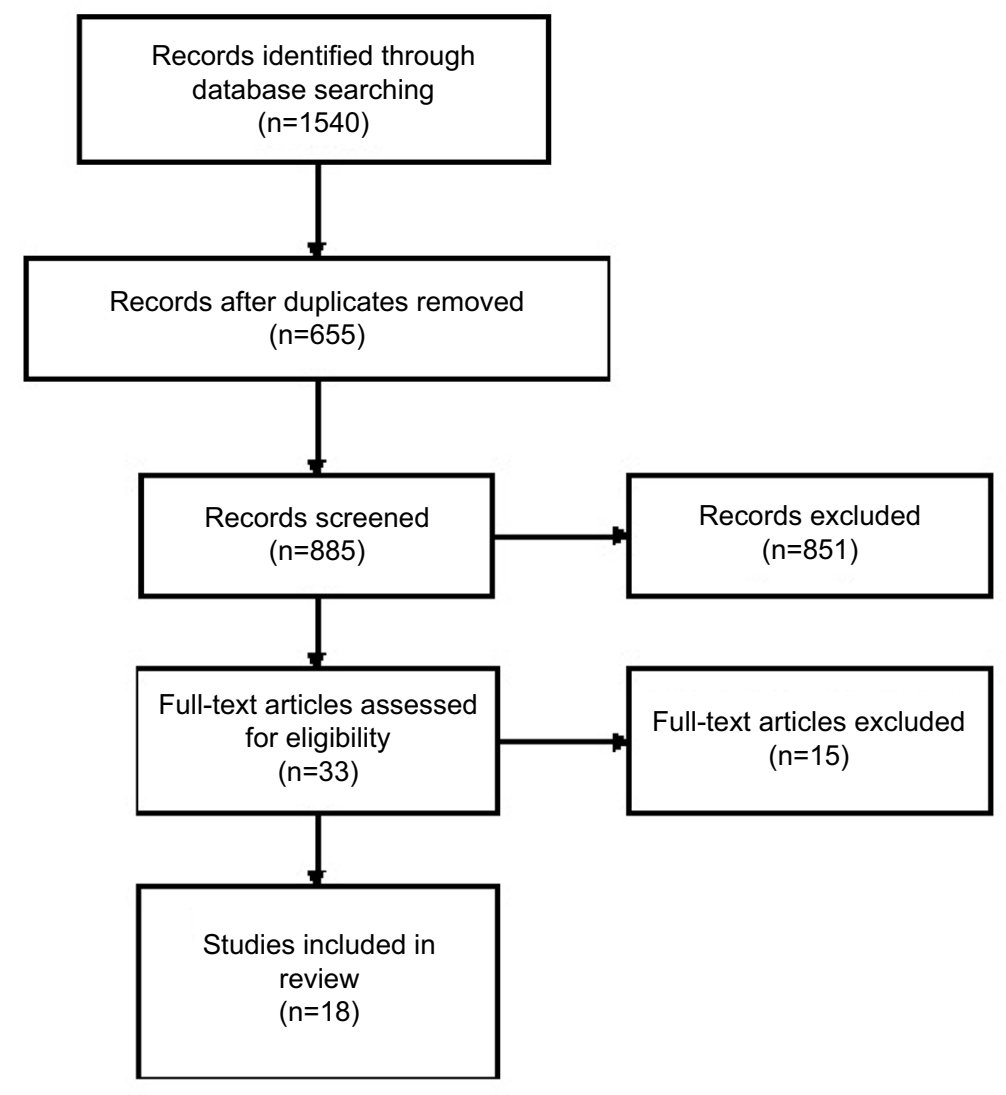

Figure I PRISMA flow diagram.

reported no change in physical activity..$^{8-10,12,14,16-18,20,23}$ Of the studies that elicited change in physical activity, three reported increased steps ranging from 1,085 to 2,334 steps/day over a period of 5-8 weeks $(p<0.05) ;{ }^{11,19,22}$ three reported increases of $28.7-34.5 \mathrm{~min} /$ day using accelerometry $(p<0.05)^{13,25}$ or 100.8 $\mathrm{min} /$ week using self-report measures $(p<0.001)^{15}$ over $8-12$ weeks of intervention; however, after adjusting for baseline physical activity, changes were no longer statistically significant in one study ${ }^{13}$ One study reported increased energy expenditure of $196.4 \mathrm{kcal} /$ day over a 6-month intervention $(p=0.02),{ }^{24}$ and another reported a greater percentage of participants with positive trends in physical activity in the intervention compared to the control group over a 3 -week intervention $(p=0.05){ }^{21}$

\section{In which populations were they successful?}

The majority of studies that reported increased physical activity were conducted in the United States, ${ }^{15,19,21,24}$ with one each conducted in Australia, ${ }^{13}$ Canada, ${ }^{22}$ Ireland, ${ }^{11}$ and the Netherlands. ${ }^{25}$ Notably, two of these targeted rural populations. ${ }^{11,22}$ Similarly, the majority of studies that either reported no change in physical activity or no difference compared to a control group from the United States, ${ }^{8,9,12,17,18}$ and one each from Australia, ${ }^{10}$ Canada, ${ }^{16}$ Korea,${ }^{20}$ the Netherlands, ${ }^{23}$ and the United Arab Emirates. ${ }^{14}$

Of the studies in which positive change in physical activity was reported, four study populations had relatively equal sex distribution, ${ }^{19,21,25}$ four were predominantly female, ${ }^{11,15,22,24}$ and one was all female. ${ }^{8}$ Sex distributions in the studies reporting no change were similar, but perhaps slightly more male dominant, with three studies reporting a relatively equal sex distribution, ${ }^{16,18,20}$ three predominantly female, ${ }^{9,12,17}$ two all female, ${ }^{8,14}$ one predominantly male, ${ }^{23}$ and one all male. ${ }^{10}$ Age did not appear to be a factor influencing the success of smartphone interventions to influence engagement and participation in physical activity. Ages ranged from late teens to eighties for both successful and unsuccessful interventions.

Of the studies in which physical activity was increased, two were conducted in people with cardiometabolic or cardiovascular risk factors, ${ }^{19,22}$ and one was conducted in each of overweight or obesity, ${ }^{24}$ chronic obstructive pulmonary disease (COPD) or type 2 diabetes, ${ }^{25}$ primary care clinic, ${ }^{11}$ sedentary, ${ }^{15}$ and healthy volunteers. ${ }^{21}$ Of the studies in which physical activity was not changed, four included participants who were overweight and/or had cardiometabolic risk factors, ${ }^{12,16,17,20}$ three included healthy volunteers, ${ }^{9,10,14}$ and 
Table I Overview of included studies

\begin{tabular}{|c|c|c|c|c|c|c|c|}
\hline Study & Country & Participants & Population & Duration & Behavior theory & $\begin{array}{l}\text { Physical } \\
\text { activity } \\
\text { measurement }\end{array}$ & $\begin{array}{l}\text { Physical activity } \\
\text { outcomes }\end{array}$ \\
\hline Choi et $\mathrm{al}^{8}$ & USA & $\begin{array}{l}\mathrm{n}=30 \text {, aged } \\
33.7 \pm 2.6 \text { years, } \\
0 \% \text { male }\end{array}$ & $\begin{array}{l}\text { Inactive } \\
\text { pregnant } \\
\text { women }\end{array}$ & 12 weeks & $\begin{array}{l}\text { Social Cognitive } \\
\text { Theory }\end{array}$ & $\begin{array}{l}\text { Step count } \\
\text { (FitBit) }\end{array}$ & No change \\
\hline Cowdery et al $^{9}$ & USA & $\begin{array}{l}\mathrm{n}=40, \text { aged } 18-69 \\
\text { years, } 15 \% \text { male }\end{array}$ & Healthy adults & 12 weeks & $\begin{array}{l}\text { Self-Determination } \\
\text { Theory }\end{array}$ & IPAQ & No change \\
\hline Gilson et $\mathrm{al}^{10}$ & Australia & $\begin{array}{l}n=44, \text { aged } \\
47.5 \pm 9.8 \text { years, } \\
100 \% \text { male }\end{array}$ & Truck drivers & 20 weeks & None & $\begin{array}{l}\text { Step count } \\
\text { (Jawbone UP } \\
\text { activity tracker) }\end{array}$ & No change \\
\hline Glynn et al" & Ireland & $\begin{array}{l}\mathrm{n}=90, \text { aged }>16 \\
\text { years, } 36 \% \text { male }\end{array}$ & $\begin{array}{l}\text { Primary care, } \\
\text { rural }\end{array}$ & 8 weeks & None & Step count (app) & $\begin{array}{l}\text { Increased }|63| \pm 3842 \\
\text { steps/day }\end{array}$ \\
\hline Hales et a $\left.\right|^{12}$ & USA & $\begin{array}{l}\mathrm{n}=9, \text { aged } \\
39 \pm 14.5 \text { years, } \\
11 \% \text { male }\end{array}$ & $\begin{array}{l}\text { Overweight } \\
\text { or obese } \\
\text { adults }\end{array}$ & 2 months & $\begin{array}{l}\text { Social Cognitive } \\
\text { Theory }\end{array}$ & $\begin{array}{l}\text { Paffenbarger } \\
\text { Physical Activity } \\
\text { Questionnaire }\end{array}$ & No change \\
\hline Hebden et $\mathrm{al}^{13}$ & Australia & $\begin{array}{l}\mathrm{n}=5 \mathrm{I}, \text { aged } \mathrm{I} 8-35 \\
\text { years, } 20 \% \text { male }\end{array}$ & $\begin{array}{l}\text { University } \\
\text { students and } \\
\text { staff }\end{array}$ & 12 weeks & Transtheoretical Model & IPAQ & $\begin{array}{l}\text { Increased light } \\
\text { intensity activity } \\
34.2 \pm 35.1 \mathrm{~min} / \text { day }\end{array}$ \\
\hline $\begin{array}{l}\text { Khalil and } \\
\text { Abdallah' }\end{array}$ & $\begin{array}{l}\text { United } \\
\text { Arab } \\
\text { Emirates }\end{array}$ & $\begin{array}{l}\mathrm{n}=8, \text { aged } 23 \pm 2.6 \\
\text { years, } 0 \% \text { male }\end{array}$ & Young adults & 2 weeks & $\begin{array}{l}\text { Theory of Reasoned } \\
\text { Action }\end{array}$ & $\begin{array}{l}\text { Step count } \\
\text { (motion } \\
\text { classifier) }\end{array}$ & No change \\
\hline King et $\mathrm{al}^{15}$ & USA & $\begin{array}{l}\mathrm{n}=63, \text { aged }>45 \\
\text { years, } 26.5 \% \text { male }\end{array}$ & Adults & 8 weeks & $\begin{array}{l}3 \text { apps: Social Cognitive } \\
\text { Theory, Social } \\
\text { Influence Theory, } \\
\text { Operant Conditioning }\end{array}$ & $\begin{array}{l}\text { CHAMPS } \\
\text { Physical Activity } \\
\text { Questionnaire }\end{array}$ & $\begin{array}{l}\text { Increased brisk } \\
\text { walking by } \\
100.8 \pm 167.0 \mathrm{~min} / \text { day }\end{array}$ \\
\hline Knight et al ${ }^{16}$ & Canada & $\begin{array}{l}\mathrm{n}=45, \text { aged } 55-75 \\
\text { years, } 44 \% \text { male }\end{array}$ & $\begin{array}{l}\text { Primary care } \\
\text { clinic }\end{array}$ & 12 weeks & $\begin{array}{l}\text { Fogg Behavior Model } \\
\text { (for counseling. None } \\
\text { for app) }\end{array}$ & $\begin{array}{l}\text { Step count } \\
\text { (pedometer) }\end{array}$ & No change \\
\hline Laing et a $\left.\right|^{17}$ & USA & $\begin{array}{l}n=180, \text { aged }>18 \\
\text { years, } 27 \% \text { male }\end{array}$ & $\begin{array}{l}\text { Primary care } \\
\text { clinic }\end{array}$ & 6 months & $\begin{array}{l}\text { Self-Regulation Theory, } \\
\text { Social Cognitive } \\
\text { Theory }\end{array}$ & Self-report & No change \\
\hline Macias et al ${ }^{18}$ & USA & $\begin{array}{l}\mathrm{n}=\mid 0, \text { aged } 22-6 \mid \\
\text { years, } 50 \% \text { male }\end{array}$ & $\begin{array}{l}\text { Psychiatric } \\
\text { disorder }\end{array}$ & 4 weeks & Stage of change & $\begin{array}{l}\text { Accelerometer } \\
\text { (Smartphone) }\end{array}$ & No change \\
\hline Martin et al ${ }^{19}$ & USA & $\begin{array}{l}\mathrm{n}=48, \text { aged } 18-69 \\
\text { years, } 54 \% \text { male }\end{array}$ & $\begin{array}{l}\text { Ambulatory } \\
\text { cardiology } \\
\text { center }\end{array}$ & 5 weeks & None & $\begin{array}{l}\text { Step count } \\
\text { (accelerometer) }\end{array}$ & $\begin{array}{l}\text { Increased by } \\
2334 \pm 17 \mid 4 \text { steps/day } \\
\text { (with text message } \\
\text { only) }\end{array}$ \\
\hline Oh et $\mathrm{a}^{20}$ & Korea & $\begin{array}{l}\mathrm{n}=422, \text { aged }>20 \\
\text { years, } 51 \% \text { male }\end{array}$ & $\begin{array}{l}\text { Obese, } \\
\text { metabolic } \\
\text { syndrome }\end{array}$ & 24 weeks & None & $\begin{array}{l}\text { Step count } \\
\text { (pedometer) }\end{array}$ & No change \\
\hline Rabbi et $\mathrm{a}^{21}$ & USA & $\begin{array}{l}\mathrm{n}=17, \text { aged } 18-49 \\
\text { years, 53\% male }\end{array}$ & Healthy adults & 3 weeks & $\begin{array}{l}\text { Learning Theory, Social } \\
\text { Cognitive Theory, Fogg } \\
\text { Behavior Model }\end{array}$ & Self-report & $\begin{array}{l}78 \% \text { of INT with } \\
\text { positive trends in } \\
\text { physical activity, vs } \\
75 \% \text { with negative } \\
\text { trends in CTL }\end{array}$ \\
\hline Stuckey et $\mathrm{al}^{22}$ & Canada & $\begin{array}{l}n=24, \text { aged } 30-71 \\
\text { years, } 25 \% \text { male }\end{array}$ & $\begin{array}{l}\text { Metabolic risk } \\
\text { factors }\end{array}$ & 8 weeks & $\begin{array}{l}\text { Counseling based on } \\
\text { Transtheoretical Model }\end{array}$ & $\begin{array}{l}\text { Step count } \\
\text { (Pedometer) }\end{array}$ & $\begin{array}{l}\text { Increased } 1085 \pm 1613 \\
\text { steps/day }\end{array}$ \\
\hline Tabak et $\mathrm{a}^{23}$ & $\begin{array}{l}\text { the } \\
\text { Nether- } \\
\text { lands }\end{array}$ & $\begin{array}{l}\mathrm{n}=15, \text { aged } \\
66 \pm 9.2 \text { years, } 60 \% \\
\text { male }\end{array}$ & COPD & 4 weeks & None & Accelerometer & No change \\
\hline $\begin{array}{l}\text { Turner- } \\
\text { McGrievy et al }{ }^{24}\end{array}$ & USA & $\begin{array}{l}\mathrm{n}=85, \text { aged } 18-60 \\
\text { years, } 25 \% \text { male }\end{array}$ & Overweight & 6 months & None & Self-report & $\begin{array}{l}\text { Increased intentional } \\
\text { PA/day } 196.4 \pm 45.9 \\
\text { kcal/day }\end{array}$ \\
\hline Verwey et $\mathrm{a}^{25}$ & $\begin{array}{l}\text { the } \\
\text { Nether- } \\
\text { lands }\end{array}$ & $\begin{array}{l}\mathrm{n}=20 \text {, aged } 4 \mathrm{I}-84 \\
\text { years, } 55 \% \text { male }\end{array}$ & $\begin{array}{l}\text { COPD or } \\
\text { Type } 2 \\
\text { Diabetes }\end{array}$ & 8-12 weeks & $\begin{array}{l}\text { Self-management with } \\
\text { Five As Model for } \\
\text { Primary Care }\end{array}$ & Accelerometer & $\begin{array}{l}\text { Increased from } \\
28.7 \pm 21.1 \text { to } \\
39.3 \pm 24.2 \mathrm{~min} / \text { day }\end{array}$ \\
\hline
\end{tabular}

Abbreviations: apps, applications; CHAMPS, Community Healthy Activities Model Program for Seniors; COPD, chronic obstructive pulmonary disease; CTL, control group; INT, intervention group; IPAQ, International Physical Activity Questionnaire. 
one each included people with major psychiatric disorders, ${ }^{18}$ pregnant women, ${ }^{8}$ and patients with COPD. ${ }^{23}$

Of the eight studies reporting positive physical activity outcomes, four required participants to use their own smartphone, ${ }^{11,19,21,24}$ three included participants with little to no smartphone experience, ${ }^{15,22,25}$ and one specified that participants needed access to text messaging and the Internet, but did not clarify how participants accessed smartphone applications. ${ }^{13}$ Of the ten studies reporting no change in physical activity, six studies required participants to use their own smartphone, $9,10,12,14,17,18$ one study reported that participants had limited smartphone experience, ${ }^{16}$ one trial allowed participants the option of using their own smartphone ( $70 \%$ chose this option) or borrowing one for study purposes, ${ }^{8}$ and two did not report whether participants were experienced with smartphone technology. ${ }^{20,23}$

\section{What were the key factors of the interventions that successfully encouraged physical activity?}

\section{Behavioral change theories}

Table 2 briefly summarizes the behavioral theories referenced in this review. Of the eight studies reporting increased physical activity, four did not report a specific behavioral change theory, ${ }^{11,19,24,25}$ although one specified using evidence-based behavioral change strategies ${ }^{19}$ and another reported use of the Five A's model for self-management in primary care. ${ }^{25}$ Two studies based their intervention on the Transtheoretical Model or stages of change, ${ }^{13,22}$ and one study included automatic feedback based on Learning Theory, Social Cognitive Theory, and the Fogg Behavior Model..$^{21}$ One study compared three apps, each based on a different behavioral change theory: an analytic app, based on Social Cognitive Theory; a social app, based on Social Influence Theory; and an affective app based on operant conditioning. ${ }^{15}$
Of the ten studies that reported no change in physical activity, five did not report an underlying theory on which the app was based, ${ }^{9,10,16,20,23}$ although two included supports external to the app based on behavioral theory. One included behavioral counseling according to the Fogg Behavior Mode ${ }^{16}$ and one included weekly motivational emails based on self-determination theory. ${ }^{9}$ Of the remaining studies, one intervention was based on the Transtheoretical Model, ${ }^{18}$ one app was developed according to Theory of Reasoned Action, ${ }^{14}$ one based its social support framework on the Social Cognitive Theory, ${ }^{12}$ and one utilized an existing app with elements of Social Cognitive Theory. ${ }^{17}$

\section{Apps' features}

A breakdown of behavioral change strategies included as features in the apps is shown in Table 3.

\section{Feedback}

Immediate feedback was provided to participants through the smartphone app in five studies that reported improved

Table 3 Features included in smartphone applications of interventions that did and did not change physical activity behaviors

\begin{tabular}{lll}
\hline Feature & $\begin{array}{l}\text { Increased } \\
\text { physical } \\
\text { activity }(\mathbf{n}=8)\end{array}$ & $\begin{array}{l}\text { No change in } \\
\text { physical activity } \\
(\mathbf{n}=10)\end{array}$ \\
\hline Feedback & $5(63 \%)$ & $2(20 \%)$ \\
Motivational cuing & $3(38 \%)$ & $2(20 \%)$ \\
Goal setting & $2(25 \%)$ & $2(20 \%)$ \\
Information and education & I (I3\%) & $2(20 \%)$ \\
Reminders & I $(13 \%)$ & $3(30 \%)$ \\
Rewards or reinforcement & I (I3\%) & I (I0\%) \\
Social support & I (I3\%) & $3(30 \%)$ \\
Gamification & $0(0 \%)$ & $\mathrm{I}(10 \%)$ \\
\hline Note: Data are prented
\end{tabular}

Note: Data are presented as $n(\%)$, where $n$ is the number of studies.

Table 2 Summary of behavioral change theories included in this review

\begin{tabular}{ll}
\hline Theory & Description \\
\hline Five A's Model & $\begin{array}{l}\text { A model to guide patient-provider interaction for behavioral change to support self-management } \\
\text { of chronic disease. } \\
\text { Three elements (motivation, ability, and trigger) must be present for a behavior to occur. } \\
\text { Fogg Behavior Model }\end{array}$ \\
$\begin{array}{l}\text { Bearning Theory/Operant Conditioning } \\
\text { of actions. Rewards are used to reinforce positive behaviors. }\end{array}$ \\
$\begin{array}{l}\text { Belf-Determination Theory } \\
\text { effective and healthy behaviors. }\end{array}$ \\
$\begin{array}{l}\text { Social Cognitive Theory } \\
\text { Social Influence Theory }\end{array}$ \\
Theory of Reasoned Action & $\begin{array}{l}\text { Behavioral change occurs based on how an individual perceives oneself in relation to others. } \\
\text { Behaviors are a result of one's attitudes and one's subjective norms. }\end{array}$ \\
Transtheoretical Model (Stages of Change) & Provides strategies for behavioral change based on an individual's readiness for action.
\end{tabular}


physical activity ${ }^{11,13,15,19,21}$ and two that reported no change in activity. ${ }^{20,23}$ An intervention group that received "smart-text" feedback increased their physical activity relative to both a group with just the app but no feedback, and a control group with neither the app nor feedback. ${ }^{19}$ Personalized messages may be important to ensure relevance of feedback. One study showed positive trends in physical activity in a group receiving personalized, context-sensitive feedback, compared to a group receiving generic suggestions for improvement. ${ }^{21}$ One study used a clinical decision-support system to generate feedback and recommendations based on personal characteristics (body weight), but physical activity was not increased. ${ }^{20}$

\section{Reminders}

One study that increased ${ }^{22}$ and three that did not increase physical activity ${ }^{12,16,18}$ used reminders as behavioral change strategies. In all four studies, however, the reminders were targeted at recording physical activity measurements rather than engaging in physical activity. Motivational cues were included in three interventions that successfully improved physical activity ${ }^{13,15,19}$ and two that did not change physical activity outcomes. ${ }^{18,23}$ Motivational cues were sent to "remind" participants of how close they were to goal achievement ${ }^{19,23}$ or to simply provide motivational messages to inspire participants to achieve their goals. ${ }^{13}$ In essence, the motivational cuing provided a reminder tailored to the participant's actions.

\section{Goal setting}

Goal setting was a feature of apps in two interventions that successfully increased physical activity ${ }^{11,15}$ and two that did not change physical activity. ${ }^{10,14}$ Two studies (one that increased $^{22}$ and one that did not increase ${ }^{16}$ physical activity) provided an individualized exercise prescription tailored to meet the participant's goals; however, goal setting was not a feature in the app.

\section{Information and education}

Three interventions, ${ }^{8,15,18}$ only one of which increased physical activity, ${ }^{15}$ included information as a built-in function of the smartphone app. Others gave brochures or included information and/or counseling at the baseline or training visit, but did not include it as an app feature.

\section{Reinforcement}

Two studies tested apps that explicitly used rewards ${ }^{9,15}$ and only one of these resulted in increased physical activity. ${ }^{15}$ In all three apps (in one study, participants could choose one of two apps ${ }^{9}$ ), rewards were virtual. Two gamification-type apps provided "supplies" to help rebuild civilization and succeed at the game, and one provided incentives by unlocking "achievements" as users progressed through the game (i.e., engaged in physically active behaviors). The third app, which increased physical activity, was based on operant conditioning principles and the reward for accomplishing physical activity was a virtual bird which appeared on the home screen and made a melodious sound while giving a thumbs-up. ${ }^{15}$

\section{Social support}

One study that positively influenced physical activity included a social component, ${ }^{15}$ while three apps that did not change physical activity included a social component. ${ }^{12,14,17}$ It should be noted, however, that one intervention based on social dynamics did not elicit statistically significant change in physical activity, but five of the seven participants showed increased steps when data were shared with group members, compared to when the social component was disabled. ${ }^{14}$

\section{Gamification}

Only two exergame apps (both included in the same study) involved gamification, but did not elicit changes in physical activity. ${ }^{9}$ Activity in the control group, however, decreased; therefore, authors concluded that the app may have prevented seasonal decline in activity. ${ }^{9}$

\section{Additional supports}

Two of the eight studies that increased physical activity either did not report additional support ${ }^{21}$ or reported that support was only available in a "help" tab. ${ }^{15}$ Three interventions provided behavioral counseling, ${ }^{11,22,25}$ two reported leveraging the patient-physician relationship or including two-way messaging between the patient and provider, ${ }^{19,22}$ and two reported online support. ${ }^{13,24}$

Three of the ten studies that did not show changes in physical activity did not report additional supports available to participants. ${ }^{14,20,23}$ The remaining seven studies reported various forms of additional supports. Two included ongoing contact with researchers in the form of virtual connection via either the $\mathrm{app}^{10}$ or a weekly motivational email, ${ }^{9}$ and one included contact with a healthcare provider. ${ }^{18}$ One intervention included behavioral counseling and goal planning as part of their intervention ${ }^{16}$ and one had only behavioral counseling. ${ }^{8}$ One reported online social support. ${ }^{18}$ One reported only assistance to download the app, a phone call 1 week into the intervention for technology troubleshooting, and an instructional video for app use, but no additional support for 
behavioral change. ${ }^{17}$ One intervention included three 20-min podcasts each week with information regarding different aspects of behavioral change. ${ }^{12}$

\section{Discussion}

In summary, the current literature showed mixed results with regard to the effectiveness of smartphone-based interventions to encourage physical activity participation. There was no clear evidence that smartphone interventions were successful in particular populations defined by country, age, sex, smartphone ownership/familiarity, or clinical diagnosis or that specific behavioral theories or features were more effective in eliciting behavioral change. Even in studies in which physical activity was increased, the statistically significant change did not often translate to participants meeting global activity guidelines. Additionally, measurement tools (e.g., pedometers or self-report) did not always allow for determination of intensity; therefore, alignment with guidelines could not be assessed. Only two studies reported that activity increased over the intervention period to, on average, meet or exceed 150 min of MVPA per week. ${ }^{15,25}$ One of these studies included patients with COPD or type 2 diabetes. ${ }^{25}$ The intervention was based on the Five A's Model for primary care and considerable additional supports were available from healthcare practitioners. ${ }^{25}$ While physical activity was increased over the intervention period, participants were, on average meeting physical activity guidelines at baseline. Another study developed and compared three smartphone apps, each grounded in a different behavioral theory: an analytic app, based on Social Cognitive Theory; a social app, based on Social Influence Theory; and an affective app based on operant conditioning. ${ }^{15}$ All three increased physical activity behaviors sufficiently to meet activity guidelines. Of the remaining six studies that reported increased physical activity (but insufficient or unknown to meet global guidelines), four were not based on behavioral theory. While some behavioral change techniques were included in these interventions, techniques were not always used optimally to support behavioral change.

Behavioral change may be best supported by tailoring interventions to individuals. While many features included in the apps have been identified as important behavioral change techniques, such as feedback, ${ }^{26}$ goal setting and monitoring, ${ }^{27-30}$ behavioral prompts or reminders, and rewards for accomplishment or progress toward the desired behavior, ${ }^{5}$ they were not always tailored to the individual's context, which may have been less effective. The evidence reported in this review supports the need for contextual feedback. Technology is advancing at a rapid rate and there is opportunity for many improvements in the current apps. Machine-learning models or data mining hold promise as efficient means to provide individualized feedback without requiring additional input from personnel..$^{21,31,32}$ Physical activity showed positive trends in a group receiving personalized, context-sensitive feedback, whereas a group receiving generic suggestions for improvement showed negative trends in physical activity. ${ }^{21}$ Importantly, feedback and recommendations were grounded in contemporary behavioral theories and personalized using a machine-learning model. Therefore, based on current behaviors tracked by the app, participants were given mostly recommendations for small goals that required little motivation and were context specific to their location, preferences, and personal data, with occasional recommendations for behaviors requiring new activities and higher motivation. ${ }^{21}$ Participants in the control group reported frustration with generalized feedback that was not actionable based on their personal context. ${ }^{21}$ It seems, however, that individualization to context may be more important than tailoring to physical characteristics. In one study, a clinical decision support system was integrated into the app to generate feedback and recommendations. ${ }^{20}$ Although feedback was personalized according to body composition and weight, context and other personal preferences may be more appropriate to include in an algorithm for personalized feedback to appropriately provide actionable recommendations, which may more effectively influence physical activity behaviors.

Goal setting has been identified as a desired feature of apps to encourage physical activity. ${ }^{27-30} \mathrm{~A}$ few apps included a goal-setting or tracking feature, and other interventions included goal setting with an exercise counselor or healthcare practitioner as an external support. Many studies had a predetermined goal (e.g., "accumulate 10,000 steps/day"). As the goal was not personalized for the participants, they may have had less motivation or desire to achieve the goal. Support, either through the app or in-person, to develop meaningful and achievable individualized goals could increase the success of smartphone-based physical activity interventions.

Self-monitoring is one of the most common functions of smartphone apps meant to initiate and/or maintain physical activity and is, in many cases, the primary or sole function. ${ }^{33}$ Self-monitoring, on its own may, fail to effectively change intended behaviors as it is an antecedent to the behavior. A greater consideration of operant learning principles, specifically reinforcement, when designing apps for behavioral change may elicit greater behavioral change. Only two studies utilized reinforcement in the form of (virtual) rewards and 
only one (which resulted in increased physical activity) was specifically based on operant theory. ${ }^{15}$ The coupling of selfmonitoring with reinforcement for positive behaviors would have more fidelity to behavioral change theory and, therefore, greater potential to elicit change. Other important factors including context, meaning, and healthcare partnerships may be incorporated to engage and retain users. ${ }^{34}$

Social networking is interesting as a component of apps as some participants enjoy the competition and support, ${ }^{14,27}$ and others strongly oppose it. ${ }^{35}$ Therefore, social networking might be an important optional feature of apps. Interventions utilizing apps that did not have built-in social support may still have benefited from social support as some studies used word-of-mouth recruitment ${ }^{16,22}$ and participants enjoyed sharing the experience with and felt motivated by their friends who were participating in the same study. ${ }^{16,22}$ Even without direct contact with researchers or clinicians, participants felt accountable to complete physical activity and study-required measures. ${ }^{22}$ Thus, social support is likely an important component to the success of behavioral change interventions to increase physical activity, whether it is included as an explicit feature of the app or whether it is sought as an adjunct through other means.

Long-term maintenance of physical activity behaviors is important to prevent or delay the onset of, and/or to manage, chronic disease. One 52-week study (which was not included in this review due to a lack of reporting of change in physical activity) was conducted in which all participants received an exercise prescription - the intervention group tracked their exercise with an app and the control group used a paper diary. ${ }^{36}$ Over the first 12 weeks, the intervention and control groups exercised, on average, 188.2 \pm 89.5 and $170.3 \pm 161.2 \mathrm{~min} /$ week, respectively, ${ }^{36}$ which complies with global physical activity recommendations. Exercise behavior was not reported at baseline or for the remaining 40 weeks; therefore, it remains unknown whether behaviors were improved at the onset of the trial and/or maintained throughout the remainder of the trial, but improvement of cardiometabolic risk factors was maintained over the study period, suggesting some maintenance of exercise behaviors. In a 12-week study, 45 participants were provided with an activity prescription and an app for activity tracking. ${ }^{16}$ There was no change in pedometer-monitored steps per day, but a baseline reading was not obtained; therefore, it is unclear whether gains were made during the intervention period. A significant increase in cardiorespiratory fitness (predicted maximal oxygen uptake; $\mathrm{pVO}_{2} \mathrm{max}$ ) suggests that activity was increased. ${ }^{37} \mathrm{~A}$ total of 6 months following completion of the study, 20 participants reported back to the laboratory for a fitness test and interview, during which they reported maintenance of physical activity behaviors, which was supported by maintenance of cardiorespiratory fitness over the follow-up period. ${ }^{37}$ It should be noted that app use was discontinued following completion of the study, suggesting that physical activity behaviors initially supported by the app may be maintained following discontinuation of use. While these long-term studies cannot support the effectiveness of smartphone interventions to initiate physical activity, there is preliminary evidence to suggest that activity, or at least cardiorespiratory fitness gains, may be maintained following continued ${ }^{36}$ or discontinued ${ }^{37}$ app use. Long-term data on the effectiveness of apps in maintaining physical activity is lacking and research is needed in this area to determine whether different behavioral change techniques need to be incorporated into apps to support physical activity maintenance versus initiation.

\section{Limitations and future considerations}

In discussing these findings, several limitations must be considered. Study quality was not assessed, which may have provided guidance toward interpreting the effectiveness of apps. Studies included in this review were primarily smallscale pilot studies. Additionally, there were few similarities between studies in terms of reported outcomes; therefore, meta-analysis could not be undertaken. While it has been suggested that, with the fast pace of the technology industry, randomized controlled trials may not be the optimal design to study smartphone-based studies, robust studies with sufficient sample sizes are needed to provide reliable data on which decisions can be based.

Surprisingly, there were a limited number of studies aimed at increasing physical activity that used change in physical activity as a primary outcome measure, which limited the number of studies included in this review. Interventions were very different in design, which made it challenging to draw conclusions regarding the effectiveness of apps in certain populations or contexts, as either the intervention or the population may have been responsible for the success of (or lack thereof) the trial. Only $50 \%$ of studies that successfully increased physical activity included interventions or apps grounded in behavioral theory, and there were no behavioral change techniques that were consistently included in successful interventions. There was also high variation in the types of behavioral change techniques included in each app; therefore, we were unable to determine whether specific combinations 
of behavioral change techniques were effective. Therefore, we cannot provide recommendations for the most appropriate theories or techniques to include in apps for increased activity. Researchers have suggested that traditional behavioral theories may not be applicable to technology-based interventions, which are interactive and adaptive, and that newer behavioral models compatible with dynamic feedback may be more suitable for app-based interventions. ${ }^{38}$

In order for apps to affect public health, apps and interventions used in research studies must be available to the general public. One of the major limitations of the literature investigating the effectiveness of smartphone interventions for physical activity engagement is that few of the studies conducted to date have used commercially available apps. Of all 18 studies included in this review, only seven used apps that were commercially available. Two studies used Healthanywhere, ${ }^{16,22}$ which offered corporate solutions, but appears to be no longer available. Another study used Fitbug, ${ }^{19}$ which will soon be available only as a corporate solution. The remaining studies used apps available in iTunes and Google Play for a cost ranging from $\$ 0.00$ to $\$ 4.40$. These apps included, Accupedo Pro Pedometer, ${ }^{11}$ myFitnessPal, ${ }^{17}$ Moves, ${ }^{9}$ Zombies Run, ${ }^{9}$ The Walk, ${ }^{9}$ and one study allowed participants to self-select any available app for tracking their activity. ${ }^{24}$ Therefore, the translation of research to practice will be limited by the availability of apps known to elicit behavioral change. Content reviews of both iTunes and Google Play have reported a lack of inclusion of evidencebased behavioral change and/or physical activity content, ${ }^{39-44}$ although the results of this review do not support the need for an app to be theory-based to affect physical activity behavior.

While apps are considered important tools for behavioral change interventions to increase physical activity because of their potential to increase reach, a number of barriers exist which should be carefully considered when designing interventions. Feedback from surveys, interviews, and/or focus groups have identified increased smartphone battery consumption, adjusting to carrying the smartphone at all times, ${ }^{45}$ slow-running apps and the requirement to log in to the app each time ${ }^{46}$ as barriers to engaging in app-based interventions. Some participants did not want to be so "connected" to their smartphone, ${ }^{15}$ and others reported concerns around privacy and invasiveness. ${ }^{29}$ In one study, barriers associated with the smartphone (availability, data coverage, data usage, costs, etc.) was the most cited reason for participant dropout. ${ }^{10}$ Issues with participation in smartphone app-based interventions for economically diverse populations, as discussed previously, should also be considered in future studies. ${ }^{6}$

\section{Conclusion}

The effectiveness of smartphone apps to encourage physical activity remains inconclusive, with no evidence of success in a particular population or context, or when a behavioral change theory was used. Future research using rigorous research design and analyses are needed.

\section{Acknowledgments}

The authors thank Mary McDiarmid, Health Sciences Librarian at Ontario Shores Centre for Mental Health Sciences, for her assistance in developing a search strategy and retrieving articles.

\section{Author contributions}

All authors contributed to the study conception. MIS completed the data analysis and drafted the manuscript. All authors contributed to interpretation of the data, critically reviewed and revised the manuscript and agree to be accountable for all aspects of the work.

\section{Disclosure}

The authors report no conflicts of interest in this work.

\section{References}

1. World Health Organization. Global Health Risks: Mortality and Burden of Disease Attributable to Selected Major Risks. Geneva: Switzerland, World Health Organization; 2009.

2. World Health Organization. Global Recommendations on Physical Activity for Health. Geneva: Switzerland, World Health Organization; 2010.

3. Colley RC, Garriguet D, Janssen I, Craig CL, Clarke J, Tremblay MS. Physical activity of Canadian adults: accelerometer results from the 2007 to 2009 Canadian Health Measures Survey. Health Rep. 2011;22(1):7-14.

4. Tucker JM, Welk GJ, Beyler NK. Physical activity in U.S.: adults compliance with the Physical Activity Guidelines for Americans. Am J Prev Med. 2011;40(4):454-461.

5. Olander EK, Fletcher H, Williams S, Atkinson L, Turner A, French DP What are the most effective techniques in changing obese individuals' physical activity self-efficacy and behaviour: a systematic review and meta-analysis. Int J Behav Nutr Phys Act. 2013;10:29.

6. Poushter J. Smartphone ownership and internet usage continues to climb in emerging economies. Washington, DC: Pew Research Center; February 22, 2016.

7. Fogg BJ. Persuasive Technology: using Computers to Change what we Think and do. Boston: Morgan Kaufmann Publishers; 2003.

8. Choi J, Lee JH, Vittinghoff E, Fukuoka Y. mHealth physical activity intervention: a randomized pilot study in physically inactive pregnant women. Matern Child Health J. 2016;20(5):1091-1101.

9. Cowdery J, Majeske P, Frank R, Brown D. Exergame apps and physical activity: the results of the ZOMBIE trial. Am J Health Educ. 2015;46(4):216-222.

10. Gilson ND, Pavey TG, Vandelanotte C, et al. Chronic disease risks and use of a smartphone application during a physical activity and dietary intervention in Australian truck drivers. Aust N Z J Public Health. 2016;40(1):91-93.

11. Glynn LG, Hayes PS, Casey M, et al. Effectiveness of a smartphone application to promote physical activity in primary care: the SMART MOVE randomised controlled trial. Br J Gen Pract. 2014;64(624):e384-e391. 
12. Hales S, Turner-McGrievy G, Fahim A, et al. A mixed-methods approach to the development, refinement, and pilot testing of social networks for improving healthy behaviors. JMIR Hum Factors. 2016;3(1):e8.

13. Hebden L, Cook A, van der Ploeg HP, King L, Bauman A, AllmanFarinelli M. A mobile health intervention for weight management among young adults: a pilot randomised controlled trial. J Hum Nutr Diet. 2014;27(4):322-332.

14. Khalil A, Abdallah S. Harnessing social dynamics through persuasive technology to promote healthier lifestyle. Comput Human Behav. 2013;29(6):2674-2681.

15. King AC, Hekler EB, Grieco LA, et al. Harnessing different motivational frames via mobile phones to promote daily physical activity and reduce sedentary behavior in aging adults. PLoS One. 2013;8(4):e62613.

16. Knight E, Stuckey MI, Petrella RJ. Health promotion through primary care: enhancing self-management with activity prescription and mHealth. Phys Sportsmed. 2014;42(3):90-99.

17. Laing BY, Mangione CM, Tseng CH, et al. Effectiveness of a smartphone application for weight loss compared with usual care in overweight primary care patients: a randomized, controlled trial. Ann Intern Med. 2014;161(10 Suppl):S5-S12.

18. Macias C, Panch T, Hicks YM, et al. Using smartphone apps to promote psychiatric and physical well-being. Psychiatr Q. 2015;86(4):505-519.

19. Martin SS, Feldman DI, Blumenthal RS, et al. mActive: a randomized clinical trial of an automated mHealth intervention for physical activity promotion. J Am Heart Assoc. 2015;4(11):pii:e002239.

20. Oh B, Cho B, Han MK, et al. The effectiveness of mobile phone-based care for weight control in metabolic syndrome patients: randomized controlled trial. JMIR Mhealth Uhealth. 2015;3(3):e83.

21. Rabbi M, Pfammatter A, Zhang M, Spring B, Choudhury T. Automated personalized feedback for physical activity and dietary behavior change with mobile phones: a randomized controlled trial on adults. JMIR Mhealth Uhealth. 2015;3(2):e42.

22. Stuckey M, Russell-Minda E, Read E, et al. Diabetes and Technology for Increased Activity (DaTA) study: results of a remote monitoring intervention for prevention of metabolic syndrome. J Diabetes Sci Technol. 2011;5(4):928-935.

23. Tabak M, op den Akker H, Hermens H. Motivational cues as real-time feedback for changing daily activity behavior of patients with COPD. Patient Educ Couns. 2014;94(3):372-378.

24. Turner-McGrievy GM, Beets MW, Moore JB, Kaczynski AT, BarrAnderson DJ, Tate DF. Comparison of traditional versus mobile app self-monitoring of physical activity and dietary intake among overweight adults participating in an mHealth weight loss program. $\mathrm{J} \mathrm{Am} \mathrm{Med}$ Inform Assoc. 2013;20(3):513-518.

25. Verwey R, van der Weegen S, Spreeuwenberg M, Tange H, van der Weijden T, de Witte L. A pilot study of a tool to stimulate physical activity in patients with COPD or type 2 diabetes in primary care. J Telemed Telecare. 2014;20(1):29-34.

26. Stephens J, Moscou-Jackson G, Allen JK. Young adults, technology, and weight loss: a focus group study. J Obes. 2015;2015:379769.

27. Ehlers DK, Huberty JL. Middle-aged women's preferred theory-based features in mobile physical activity applications. J Phys Act Health. 2014;11(7):1379-1385.

28. Rabin C, Bock B. Desired features of smartphone applications promoting physical activity. Telemed J E Health. 2011;17(10):801-803.

29. Ramanathan N, Swendeman D, Comulada WS, Estrin D, Rotheram-Borus MJ. Identifying preferences for mobile health applications for selfmonitoring and self-management: focus group findings from HIV-positive persons and young mothers. Int J Med Inform. 2013;82(4):e38-e46.
30. Tang J, Abraham C, Stamp E, Greaves C. How can weight-loss app designers' best engage and support users? A qualitative investigation. Br J Health Psychol. 2015;20(1):151-171.

31. Ayubi SU, Parmanto B. PersonA: Persuasive social network for physical Activity. In: Conference proceedings; Annual International Conference of the IEEE Engineering in Medicine and Biology Society. IEEE Engineering in Medicine and Biology Society. Conference. 2012; 2153-2157.

32. Seto E, Hua J, Wu L, et al. Models of individual dietary behavior based on smartphone data: the influence of routine, physical activity, emotion, and food environment. PLoS One. 2016;11(4):e0153085.

33. Coughlin SS, Whitehead M, Sheats JQ, Mastromonico J, Smith S. A review of smartphone applications for promoting physical activity. Jacobs J Community Med. 2016;2(1):pii:021.

34. Miyamoto SW, Henderson S, Young HM, Pande A, Han JJ. Tracking health data is not enough: a qualitative exploration of the role of healthcare partnerships and mHealth technology to promote physical activity and to sustain behavior change. JMIR Mhealth Uhealth. 2016;4(1):e5.

35. Gowin M, Cheney M, Gwin S, Franklin Wann T. Health and fitness app use in college students: a qualitative study. Am J Health Educ. 2015;46(4):223-230.

36. Petrella RJ, Stuckey MI, Shapiro S, Gill DP. Mobile health, exercise and metabolic risk: a randomized controlled trial. BMC Public Health. 2014;14:1082.

37. Knight E, Petrella RJ. Prescribing physical activity for healthy aging: longitudinal follow-up and mixed method analysis of a primary care intervention. Phys Sportsmed. 2014;42(4):30-38.

38. Riley WT, Rivera DE, Atienza AA, Nilsen W, Allison SM, Mermelstein R. Health behavior models in the age of mobile interventions: are our theories up to the task? Transl Behav Med. 2011;1(1):53-71.

39. Cowan LT, Van Wagenen SA, Brown BA, et al. Apps of steel: are exercise apps providing consumers with realistic expectations?: a content analysis of exercise apps for presence of behavior change theory. Health Educ Behav. 2013;40(2):133-139.

40. Deterding S, Dixon D, Khaled R, Nacke L. From game design elements to gamefulness: defining gamification. Paper presented at: Academic MindTrek Conference: Envisioning Future Media Environments; 2011; September 28-30th, 2011 in Tampere, Finland. (Published by ACM, New York, NY, USA).

41. Direito A, Dale LP, Shields E, Dobson R, Whittaker R, Maddison R. Do physical activity and dietary smartphone applications incorporate evidence-based behaviour change techniques? BMC Public Health. 2014;14:646.

42. Knight E, Stuckey MI, Prapavessis H, Petrella RJ. Public health guidelines for physical activity: is there an app for that? A review of android and apple app stores. JMIR Mhealth Uhealth. 2015;3(2):e43.

43. Middelweerd A, Mollee JS, van der Wal CN, Brug J, Te Velde SJ. Apps to promote physical activity among adults: a review and content analysis. Int J Behav Nutr Phys Act. 2014;11:97.

44. West JH, Hall PC, Hanson CL, Barnes MD, Giraud-Carrier C, Barrett J. There's an app for that: content analysis of paid health and fitness apps. J Med Internet Res. 2012;14(3):e72.

45. Casey M, Hayes PS, Glynn F, et al. Patients' experiences of using a smartphone application to increase physical activity: the SMART MOVE qualitative study in primary care. Br J Gen Pract. 2014;64(625):e500-e508.

46. Hebden L, Cook A, van der Ploeg HP, Allman-Farinelli M. Development of smartphone applications for nutrition and physical activity behavior change. JMIR Res Protoc. 2012;1(2):e9. 
The International Journal of General Medicine is an international, peer-reviewed open-access journal that focuses on general and internal medicine, pathogenesis, epidemiology, diagnosis, monitoring and treatment protocols. The journal is characterized by the rapid reporting of reviews, original research and clinical studies across all disease areas.
The manuscript management system is completely online and includes a very quick and fair peer-review system, which is all easy to use. Visit http://www.dovepress.com/testimonials.php to read real quotes from published authors.

Submit your manuscript here: https://www.dovepress.com/international-journal-of-general-medicine-journal 